\title{
A Phenomenographic Approach for Exploring Conceptions of Learning Marketing among Undergraduate Students
}

\author{
Hung-Ming Lin \\ Department of Business Administration, Minghsin University of Science and Technology \\ No.1 Hsin Hsing Rd., Hsinchu 30401, Taiwan
}

Tel: 886-3-559-3142\#1827Ｅ-mail: hmlin@must.edu.tw

Han-Jen Niu (Corresponding author)

Department of Management Sciences, Tamkang University

151 Ying-chuan Rd., Tamsui 25137, Taiwan

Tel: 886-2-2621-5656\#2695Ｅ-mail: freyaniu@gmail.com

Received: July 31, 2011 Accepted: August 13, 2011 doi:10.5296/ber.v1i1.829

\begin{abstract}
This paper describes ongoing research investigating students' conceptions of learning marketing. This empirical study was conducted using a phenomenographic approach to analyze data from individual semi structured interviews with twenty-four Taiwanese university students. The six categories of conceptions of learning marketing were identified, including learning marketing as 'memorizing,' 'testing,' 'applying,' 'gaining higher status,' 'understanding' and 'seeing in a new way.' In contrast with other learning domains, the results illustrate that 'applying' was conceptualized as the major feature of learning marketing for all interviewed students. Moreover, most of the students consider 'applying' and 'understanding' to be closely related when learning marketing.
\end{abstract}

Keywords: Conceptions of learning marketing, Marketing education, Phenomenographic approach, Taiwan 


\section{Introduction}

In the 1970s, a group of Swedish researchers developed the qualitative research approach known as phenomenography. The researchers' goal was to explore people's understanding of their experience of the world around them. This goal was achieved, and the outcome is a distinctive qualitative research approach that has application within the social sciences.

The phenomenographic approach is noted as being distinctive in that it identifies similarities and differences in the way we experience and understand phenomena in the world around us. It follows that in higher education research, it has been used to recognize how students experience and understand 'learning' (e.g., Eklund-Myrskog, 1998; Marton, Dall'Alba, \& Beaty,1993; Tsai, 2004; Virtanen \& Lindblom-Ylänne, 2010). Within this field of research, much phenomenographic research has sought to contribute to the knowledge of learning by making evident the different ways learners perceive their learning (Marton \& Booth, 1997). If the students' different ways of experiencing learning can be obtained, it will facilitate educators to improve students' learning outcomes, and provide a foundation for developing more appropriate curricula or instructional approaches in their class. Therefore, in the current study, the phenomenographic approach is employed in a careful investigation of how students interpret "learning marketing".

\subsection{Phenomenographic research}

Phenomenography is an interpretive research approach that seeks to describe phenomena in the world as others see them, the object of the research being to identify variations in ways of experiencing the phenomenon of interest (Marton \& Booth, 1997). It originated with Ference Marton and his colleagues at the University of Goteborg in Sweden. The term 'phenomenography' was coined in 1979 and appeared in the literature related to conceptions of learning for the first time two years later (Marton, 1981). Such ways of differentiating should prove useful in understanding other people's understandings (Marton, 1986, 1988). Since the 1970s, phenomenography has developed into a distinctive qualitative approach to understanding not only learning, but a broad range of phenomena. Marton (1981) described this approach as "research which aims at description, analysis, and understanding of experiences; that is, research which is directed towards experiential description" (p.180).

The outcomes of phenomenographic research are presented as a hypothetical 'outcome space', developed from the researcher analysis and interpretations of the data collected through a series of deep and open-ended interviews from a sample group (Marton, 1988). The outcome space is represented analytically as a limited number of qualitatively different ways of experiencing the phenomenon, including the structural relationships between these different ways of experiencing. This structuring of the outcome space involves highlighting key aspects or 'dimensions of variation' that have been found, to link and separate the different ways of experiencing the phenomenon constituted in the outcome space (Marton \& Booth, 1997). For example, the six categories of conceptions of learning identified by Marton et al. (1993), that is, 'increasing one's knowledge', 'memorizing,' 'applying,' 'understanding,' 'seeing in a different way' and 'changing as a person,' (changing in the way a person sees themselves) are the outcome space for learning. Each category represents sample students' 
different ways of experiencing learning, and these categories show structural and hierarchical relationships for conceptualizing learning. Different ways of experiencing learning and different levels of learning among individual students are more efficiently accessed through the outcome space of learning.

Phenomenography is one approach for dealing with the problem of analyzing the meaning that people attribute to the world (Säljö, 1988). Marton (1981) has categorized phenomenography into three lines of research. The first line of research has continued to concentrate on general aspects of learning. The second line of research concerns the conceptions of learning in domains such as engineering, nursing, or science. The third line of research is described as "pure" phenomenographic interest, and is concerned with characterizing the way in which people conceive various aspects of their world. To continue research on the conceptions of learning in a specific domain, and since almost none of the studies in marketing education have explored students' conceptions of learning marketing, the phenomenographic approach is used here to explore students' conceptions of marketing learning in particular.

\subsection{Conceptions of Learning}

To acquire a better understanding of learning, researchers have devoted efforts to careful investigation of how an individual describes what learning is. The earliest research work into students' conceptions of learning was conducted by Säljö (1979). In Säljö's (1979) study, five qualitatively different and hierarchically related conceptions of learning were identified using a phenomenographic method; learning was conceptualized as: (1) increase of knowledge, (2) memorizing, (3) acquisition of facts, procedures that can be retained and/or utilized in practice, (4) abstraction of meaning, and (5) an interpretative process aimed at the understanding of reality. The phenomenographic method, which combines interviews and protocol and discourse analyses, is used to identify students' qualitatively different, hierarchically related, conceptions of learning, and is frequently employed in this line of research (Richardson, 1999). Säljö's (1979) categorization of the conceptions of learning has been supported by subsequent studies (e.g., Dahlin \& Regmi, 1997; Eklund-Myrskog, 1998; Marton et al., 1993). A following study completed by Marton et al. (1993) also found similar conceptions of learning, for example, 'increasing one's knowledge' (similar to Säljö's 'increase of knowledge'), 'memorizing' (similar to Säljö's 'memorizing'), 'applying' (similar to Säljö's 'acquisition of facts, procedures that can be retained and/or utilized in practice'), 'understanding' (similar to Säljö's 'abstraction of meaning'), 'seeing in a different way' (similar to Säljö's 'an interpretative process aimed at the understanding of reality'). However, in a study by Marton et al. (1993), a new conception, learning as 'personal change', was identified.

In Marton et al.'s (1993) study, the first three conceptions, 'increasing one's knowledge,' 'memorizing' and 'applying,' are related to a "quantitative" view of learning, as these conceptions place more emphasis on what is learned (the 'what' aspect of learning). The quantitative view implies that learning is a process of accumulation or copying of new and accurate information in the memory. Therefore, these three conceptions are regarded as 
"reproductive" conceptions of learning. However, the latter three conceptions, 'understanding,' 'seeing in a different way' and 'changing as a person' are related to the "qualitative" view of learning, as these conceptions may focus more on how something is learned (the 'how' aspect of learning). The qualitative view implies that learning involves an active process of seeking meaning, leading to some kind of transformation in one's view of things or of the self. Thus, these three conceptions are viewed as "transformative" conceptions of learning (Biggs, 1994). Moreover, the process (the "how" aspect) of learning becomes more important than what is learned, as it will ultimately influence the personal life of each individual (McLean, 2001). Consequently, the quantitative view of learning is seen as a lower-level conception of learning, while the qualitative view of learning is viewed as higher-level. As Marton et al. $(1993,1997)$ suggested, the quantitative view is oriented to a focus on 'the signs' (i.e. on the learning materials as such), while the qualitative view is oriented to a focus going beyond the signs or the learning material to 'the signified' (i.e. that to which the learning material refers).

The conceptions of learning are related to educational contexts. Previous studies have found that students majoring in different domains (such as in nursing or engineering) or in different educational environmental contexts (such as in Taiwan or Nepal), express quite different conceptions of learning (Dahlin \& Regmi, 1997; Eklund-Myrskog, 1998; Lin \& Tsai, 2008; Marshall, Summer, \& Woolnough, 1999; Virtanen \& Lindblom-Ylänne, 2010). For example, other than those revealed by previous studies (Marton et al., 1993; Eklund-Myrskog ,1998; Marshall et al., 1999), Tsai (2004) found two new categories, 'testing' and 'calculating' in the domain of science. Tsai (2004) indicated that these two new categories of learning might be identified in different educational environments or different learning domains. Therefore, an individual student may have quite different conceptions in different domains of learning. That is, students' understandings about the domain knowledge still play a role in their conceptions of learning in the specific domain (Hofer \& Pintrich, 1997). The domain knowledge of marketing is different from the domain knowledge of other academic disciplines. The conceptions of learning marketing may also be different from those of other domains (e.g., science).

Recently, much marketing education research has concentrated on how to enhance students' learning outcomes in the marketing discipline (e.g., Duke, 2002; Sautter, 2007; Young, Klemz, \& Murphy, 2003). Several studies have suggested that students' learning outcomes are related to their learning styles (Bliuc et al., 2010; Young et al., 2003; Zeegers, 2001). For example, Zeegers (2001) has illustrated that the deep approach shows a consistent positive correlation with assessment outcomes. Burnett, Pillay, and Dart (2003) indicated further that students' learning styles are correlated to their conceptions of learning. If students' conceptions of learning marketing can be carefully explored, it will assist educators to promote their learning outcomes. Therefore, the main purpose of the present study is to explore students' conceptions of learning marketing.

\section{Method}

\subsection{Participants}


Research data for this study were collected through individual interviews with 24 students from two universities in Taiwan. As Bowden and Green (2005) suggested, in a phenomenographic study, the number of interview participants should ensure sufficient variation in ways of seeing, but not be so many that it makes it difficult to manage the data. In practice, most phenomenographers find that between 20 and 30 participants meet the two criteria. All of the participants were majoring in Business Administration, and were taking marketing management courses. Eleven female and fourteen male students (average age: 22.03) were interviewed for this study.

\subsection{Data collection}

The research data were gathered by interviewing the sample students. Each student was interviewed individually by the authors. The interview was undertaken in a semi-structured way. The guiding interview questions were based on the questions from the studies done by Marshall et al. (1999) and Tsai (2004), as follows:

- What do you mean by 'learning marketing'? Or, in your view, what is 'learning marketing'?

- How do you know when you have learned something about marketing?

- How do you learn marketing and for what?

All of the individual interviews were tape-recorded and transcribed word for word. The interviews were conducted in Chinese and then fully transcribed for further analysis. The verbatim transcripts of these interviews were the main data sources for analyzing students' conceptions of learning marketing.

\subsection{Data analysis}

The analysis of the verbatim transcripts of the interview data was conducted using a phenomenographic method. Similar to the method used by Tsai (2004), first, the researchers read all the interview transcripts and marked the parts where students expressed their main ideas about learning marketing. They then considered the selected parts in every interview transcript, underlined the most important sentences, and marked keywords which characterized the student's views of learning marketing. By comparing the underlined sentences and the keywords derived from the transcripts, the content-specific similarities and differences between students' interview replies about their views of learning marketing were explored and summarized. Then, the researchers developed 'qualitatively different' categories of descriptions that were used to characterize the conceptions of learning marketing of these Business Administration majors.

\subsection{Reliability checks}

The technique of inter-judge reliability is mostly used to check the reliability of categories of descriptions within phenomenographic studies (Dahlin \& Regmi, 1997; Tsai, 2004). The reliability of the description categories can be claimed on the basis of the percentage agreement between all the coders' classifications before and after consultation. Säljö (1988) 
believed that an agreement of $80 \%$ to $90 \%$ after consultation was appropriate. In this study, two researchers classified the students' conceptions of learning marketing. For the interview data which they did not agree upon, the researchers reviewed the interview transcripts again and discussed them case by case, and then determined a final categorization together. The 88 $\%$ agreement of the two researchers in this study is acceptable.

\section{Findings}

According to the phenomenographic analysis, six qualitatively different conceptions of learning marketing were identified in this study. The findings are described below.

Learning marketing as 'memorizing' (M)

In the first category, students view learning marketing as the memorization of theories and definitions. For these students, the purpose of learning marketing is to discuss with others and extend their knowledge. For example, students responded that:

Memorization is essential when you learn marketing. (\#1)

I don't really understand marketing management in class from lectures, but I try to memorize some theories or definitions first. (\#12)

Students are used to using memorization techniques to learn marketing. They memorize marketing theories or terminology is for discussing the marketing managerial issues with others. In this way, Memorization is not true learning because interpretation is ignored.

Learning marketing as 'testing' $(\mathrm{T})$

In this category, students conceptualize learning marketing as preparing for tests; their purpose for learning marketing is to pass the examinations.

Testing is the purpose of learning marketing. (\#5)

Because the teacher's main way of evaluating and assessing student's achievement is written examinations, learning marketing for students mean preparing for the tests. (\#13)

In this category, the students emphasize the tests when learning marketing. One student (\#5) even claimed that 'learning marketing is only for testing'.

Learning marketing as 'gaining higher status' $(\mathrm{G})$

In this category, students regard learning marketing as gaining higher status, such as obtaining a better marketing job, and promoting self competition after graduation. Their purpose of learning marketing is to be more socialized in a group with good communicative competence. That can help them to be more competitive and to find a good marketing job.

Learning marketing can enhance my marketing skills and marketing ability, such selling skill, how communicate with customers, how to advertise a product. (\#13)

Learning marketing is very helpful for competition and job interviews. (\#17)

Students in this category highly value the outcomes of learning marketing. They believe that 
learning marketing may enhance their marketing ability, so that they will have more opportunities to gain higher status in the job market.

Learning marketing as applying (A)

In this category, applying is conceptualized as the main feature of learning marketing. Consequently, a successful application of received knowledge constitutes the main purpose of learning marketing. For instance, students stated that:

Learning marketing needs you to apply it. Application can let you know whether you understand it or not. (\#6)

When you participate in some activities, or school clubs, or get along with people, you can apply marketing knowledge. Then, you will know how well you have learned. (\#24)

Learning marketing is deemed as applying knowledge to solve a variety of life associated problems. Although the interviewed students do not have real work experience, they still try to apply knowledge in the situations in which they are engaged, such as daily life and school clubs. In addition, 'applying' is also viewed as an important way to evaluate whether they really understand the learned knowledge. The relationship between 'applying' and 'understanding', for some students, seems to be very close.

Learning marketing as understanding $(\mathrm{U})$

In this category, a true understanding is conceptualized as the chief feature of learning marketing.

Understanding is the first step of learning marketing. (\#11)

Learning marketing requires a real understanding. If you understand the knowledge, you can apply it in many areas. (\#18)

Students in this category evaluate their learning of marketing on the basis of their ability to apply acquired marketing knowledge.

Learning marketing as seeing in a new way (S)

In the final category, learning marketing is viewed as gaining a new perspective. The acquisition of marketing managerial knowledge is to obtain a new way to interpret matters related to business management. For instance, students stated that:

Learning marketing brings new perspectives for me. This is interesting. (\#22)

I will try to think in a different way. (\#23)

I find my perspectives have become broader. (\#24)

These students believe that learning marketing helps them acquire a new way of seeing and thinking. Their outlook on life seems to be extended after acquiring more knowledge of marketing management.

\subsection{Distribution of students' conceptions of learning marketing}


The purpose of this study is to characterize variations in conceptions of learning marketing among the interviewed students, rather than to focus on classifying or labeling individual students. Therefore, for a fuller representation of the interviewed students' conceptions of learning marketing, each student was allowed to be included in one or more categories according to his/her conceptions of learning marketing. The distribution of each student's conceptions of learning marketing among the six categories is presented in Table 1.

Table 1. Students' conceptions of learning marketing

\begin{tabular}{|c|c|c|c|c|c|c|}
\hline Student ID & Memorizing & Testing & Gaining higher status & Applying & Understanding & Seeing in a new way \\
\hline $1^{*}$ & $\sqrt{ }$ & & & $\sqrt{ }$ & & \\
\hline 2 & $\sqrt{ }$ & $\sqrt{ }$ & & $\sqrt{ }$ & $\sqrt{ }$ & \\
\hline 3 & $\sqrt{ }$ & & & $\sqrt{ }$ & $\sqrt{ }$ & \\
\hline 4 & $\sqrt{ }$ & & & $\sqrt{ }$ & & \\
\hline 5 & $\sqrt{ }$ & $\sqrt{ }$ & & $\sqrt{ }$ & $\sqrt{ }$ & \\
\hline 6 & & & & $\sqrt{ }$ & $\sqrt{ }$ & $\sqrt{ }$ \\
\hline 7 & . & & & $\sqrt{ }$ & $\sqrt{ }$ & \\
\hline 8 & $\sqrt{ }$ & & & $\sqrt{ }$ & $\sqrt{ }$ & \\
\hline 9 & & & & $\sqrt{ }$ & $\sqrt{ }$ & \\
\hline 10 & $\sqrt{ }$ & & & $\sqrt{ }$ & $\sqrt{ }$ & \\
\hline 11 & $\sqrt{ }$ & & & $\sqrt{ }$ & $\sqrt{ }$ & \\
\hline 12 & $\sqrt{ }$ & $\sqrt{ }$ & & $\sqrt{ }$ & $\sqrt{ }$ & \\
\hline 13 & $\sqrt{ }$ & $\sqrt{ }$ & $\sqrt{ }$ & $\sqrt{ }$ & $\sqrt{ }$ & \\
\hline 14 & $\sqrt{ }$ & $\sqrt{ }$ & & $\sqrt{ }$ & $\sqrt{ }$ & $\sqrt{ }$ \\
\hline 15 & $\sqrt{ }$ & $\sqrt{ }$ & $\sqrt{ }$ & $\sqrt{ }$ & $\sqrt{ }$ & $\sqrt{ }$ \\
\hline 16 & $\sqrt{ }$ & $\sqrt{ }$ & $\sqrt{ }$ & $\sqrt{ }$ & $\sqrt{ }$ & \\
\hline 17 & & $\sqrt{ }$ & $\sqrt{ }$ & $\sqrt{ }$ & $\sqrt{ }$ & \\
\hline 18 & & & $\sqrt{ }$ & $\sqrt{ }$ & $\sqrt{ }$ & \\
\hline 19 & & $\sqrt{ }$ & & $\sqrt{ }$ & & $\sqrt{ }$ \\
\hline 20 & & $\sqrt{ }$ & $\sqrt{ }$ & $\sqrt{ }$ & $\sqrt{ }$ & \\
\hline 21 & & $\sqrt{ }$ & & $\sqrt{ }$ & $\sqrt{ }$ & \\
\hline 22 & & & & $\sqrt{ }$ & $\sqrt{ }$ & $\sqrt{ }$ \\
\hline 23 & & & & $\sqrt{ }$ & & $\sqrt{ }$ \\
\hline 24 & & & $\sqrt{ }$ & $\sqrt{ }$ & $\sqrt{ }$ & $\sqrt{ }$ \\
\hline Total & 13 & 11 & 7 & 24 & 20 & 7 \\
\hline
\end{tabular}

* A sequential identifying number for each student

\section{Discussion and Conclusions}

Six categories of conceptions of learning marketing have been identified, including learning markeitng as 'memorizing,' 'testing,' 'applying,' 'gaining higher status,' 'understanding' and 'seeing in a new way.' The 'applying' conception of learning marketing was highly emphasized by the interviewed students.

The case-teaching method has been used in the marketing programs for many years. In 
general, the cases involve a description of a business situation, requiring students to identify and solve general or specific business problems embedded in the situation (Little, Brookes, \& Palmer, 2008). They are very usual as contexts for which to apply the marketing concepts and theories, and allow students to see how marketing may be practiced in the real world, and are especially useful where students have no or limited prior experience in employment (e.g., Forman, 2006; Harrison-Walker, 2000). In this study, the interviewed students' high level of agreement with the 'applying' category indicates that marketing knowledge, by nature, should be applied in practice. This result demonstrates that the case-teaching method is close to students' beliefs about the nature of marketing knowledge. Therefore, in general, most students prefer the case-teaching method in marketing courses, as it can help them obtain 'real' understanding of marketing concepts and theories.

Previous studies have shown that students' conceptions of learning are shaped by culture (Dahlin \& Regmi, 1997; Marton et al., 1997; Marton, Wen, \& Wong, 2005; Purdie et al., 1996). For example, Purdie et al. (1996) showed that Australian and Japanese students had quite different conceptions of learning. Among students' conceptions of learning, the relationship between memorization and understanding are particularly highlighted. Dahlin and Regmi (1997) indicated that memorization and understanding are often deemed as opposites in Western thinking. However, Marton et al. (1997) found that learners in Hong Kong consider memorization and understanding to be closely related. A similar view about understanding and memorization seems to be present among Taiwanese students. As illustrated in Table 1, the 'memorization' category overlaps with the 'understanding' category in some students' conceptions of learning marketing (e.g., \#2, \#3, and \#5). For example, one student (\#3) stated that 'when I learn marketing, I'll memorize first and then seek to comprehend.' Understanding could probably co-exist with memorization, and is based on the students' memorization. Therefore, for some Taiwanese students, it is still practical to understand and memorize simultaneously when learning marketing.

In addition, according to Tsai's (2004) research, student beliefs about school knowledge and learning, and conceptions are related to domain-specific epistemologies. Learning conceptions can be shaped by domain-specific factors, too. In this study, most students' conceptions of learning marketing overlap 'application' and 'understanding' (see Table 1 for details). For example, one student (\#6) stated that 'Learning marketing needs you to apply it. Application can let you know whether you understand it or not.' Application and understanding can coexist in the students' conceptions of learning marketing. This result is totally different from other learning domains.

One possible pedagogical contribution this study may have related to the six hierarchical cognitive processes included in revised versions of Bloom's taxonomy of learning, namely remembering, understanding, applying, analyzing, evaluating, and creating (c.f., Krathwohl, 2002). The hierarchical categories of the cognitive processes of revised Bloom's taxonomy seem to have some resemblance to conceptions of learning. However, the taxonomy of educational objectives emphasized what educators expect or intend students to learn as a result of instruction, but conceptions of learning might represent what students view about learning. Also, students' conceptions of learning marketing may be said to represent their 
purposes of learning marketing. Marketing educators are urged to use the results of the present study to evaluate their students' conceptions of learning marketing and, simultaneously, plan marketing education curricula that are in sync with revised versions of Bloom's taxonomy of learning.

In this study, six qualitatively different conceptions of learning marketing were identified, including 'memorizing,' 'testing,' 'gaining higher status,' 'applying,' 'understanding' and 'seeing in a new way.' Based on the hierarchical conceptions of learning proposed by Marton et al. (1993), the first four conceptions can be regarded as "quantitative-oriented" or "reproductive," while the last two conceptions are "qualitative-oriented" or "transformative." As McLean (2001) concluded, students' academic achievement is related to the conceptions of learning that they hold. In this study, students with superior academic records expressed more transformative conceptions of learning ('understanding' and 'seeing in a new way') than did their less academically achieving peers. According to Table 1, the students in this study tend to hold transformative conceptions of learning marketing ('understanding' and 'seeing in a new way') less than the reproductive conceptions of learning marketing ('memorizing,' 'testing,' 'gaining higher status' and 'applying'). Based on McLean's (2001) results, we predict that some students in this study will attain unfavorable achievement outcomes when they are engaged in learning marketing. How to change students' reproductive conceptions of learning (such as 'memorizing' and 'testing') into transformative conceptions of learning (such as 'understanding' and 'seeing in a new way') may become an essential issue for future research.

\section{Acknowledgements}

Funding of this research was provided by the National Science Council, Taiwan, under grant NSC 98-2511-S159-001-MY2 and 100-2410-H-159-002.

\section{References}

Biggs, J. (1994). Student learning research and theory: Where do we currently stand?, in G. Gibbs (ed.) Improving student learning: Using research to improve student learning, Oxford: Oxford Centre for Staff Development, pp.1-19.

Bliuc, A. M., Ellis, R .A., Goodyear, P., \& Piggott, L. (2010). Learning through face-to-face and online discussions: Associations between students' conceptions, approaches and academic performance in political science. British Journal of Educational Technology, 41, pp.512-24. http://dx.doi.org/10.1111/j.1467-8535.2009.00966.x

Bowden, J. A., \& Green, P. (2005). Doing developmental phenomenography. Melbourne: PMIT University Press.

Burnett, P. C., Pillay, H., \& Dart, B. C. (2003). The influences of conceptions of learning and learner self-concept on high school students' approaches to learning. School Psychology International, 24, pp.54-66. http://dx.doi.org/10.1177/0143034303024001621

Dahlin, B., \& Regmi, M. P. (1997). Conceptions of learning among Nepalese students. Higher Education, 33, pp.471-93. http://dx.doi.org/10.1023/A:1002992411868 
Duke, C. R. (2002). Learning outcome: Comparing student perceptions of skill level and importance. Journal of Marketing education, 24, pp.203-17. http://dx.doi.org/10.1177/0273475302238043

Eklund-Myrskog, G. (1998). Students' conceptions of learning in different educational contexts. Higher Education, 35, pp.299-316. http://dx.doi.org/10.1023/A:1003145613005

Forman, H. (2006). Participative case studies: Integrating case writing and a traditional case study approach in a marketing context. Journal of Marketing Education, 28, pp.106-13. http://dx.doi.org/10.1177/0273475306288398

Harrison-Walker, L. J. (2000). A comprehensive pedagogy for dialectic team-based marketing management case analysis. Journal of Education for Business, 75, pp.241-45. http://dx.doi.org/10.1080/08832320009599022

Hofer, B. K., \& Pintrich, P. R. (1997). The development of epistemological theories: Beliefs about knowledge and knowing and their relation to learning. Review of Educational Research, 67, pp.88-140.

Krathwohl, D. R. (2002). A revision of Bloom's taxonomy: An overview. Theory into Practice, 63, pp.212-18. http://dx.doi.org/10.1207/s15430421tip4104_2

Lin, H.-M., \& Tsai, C.-C. (2008). Conceptions of learning management among undergraduate students in Taiwan. Management Learning. 39, pp.561-78. http://dx.doi.org/10.1177/1350507608096041

Little, V., Brookes, R., \& Palmer, R. (2008). Research-informed teaching and teaching-informed research: The contemporary marketing practices (CMP) living case study approach to undertaking marketing practice, Journal of Business and Industrial Marketing, 23, pp.124-34. http://dx.doi.org/10.1108/08858620810850245

Marshall, D., Summer, M., \& Woolnough, B. (1999). Students' conceptions of learning in an engineering context. Higher Education, 38, pp.291-309. http://dx.doi.org/10.1023/A:1003866607873

Marton, F. (1981). Phenomenography-describing conceptions of the world around us. Instructional Science, 10, pp.177-200. http://dx.doi.org/10.1007/BF00132516

Marton, F. (1986). Phenomenography: A research approach to investigating different understandings of reality. Journal of Thought, 21, pp.28-49.

Marton, F. (1988). Phenomenography: Exploring different conceptions of reality. In D. M. Fetterman (eds), Qualitative approaches to evaluation in education: The silent scientific revolution, New York: Praeger, pp.176-298.

Marton, F. \& Booth, S. (1997). Learning and awareness. Mahwah, New Jersey: Erlbaum.

Marton, F., Dall'Alba, G., \& Beaty, E. (1993). Conceptions of learning. International Journal of Educational Research, 19, pp.277-300. 
Marton, F., Wen, Q., Wong, K. (2005). 'Read a hundred times and the meaning will appear ...' Changes in Chinese University students' views of the temporal structure of learning. Higher Education, 49, pp.291-318. http://dx.doi.org/10.1007/s10734-004-6667-z

McLean, M. (2001). Can we relate conceptions of learning to student academic achievement?. Teaching in Higher Education, 6, pp.399-413. http://dx.doi.org/10.1080/13562510120061241

Purdie, N., Hattie, J., \& Douglas, G. (1996). Student conceptions of learning and their use of self-regulated learning strategies: A cross-culture comparison, Journal of Educational Psychology, 88, pp. 87-100. http://dx.doi.org/10.1037/0022-0663.88.1.87

Richardson, J. T. E. (1999). The concepts and methods of phenomenographic research. Review of Educational Research, 69, pp.53-82.

Säljö, R. (1979). Learning in the learner's perspective I. Some commonsense conceptions. Gothenburg, Sweden: Institute of Education, University of Gothenburg.

Säljö, R. (1988). Learning in educational settings: Methods of inquiry. In P. Ramsden (eds.), improving learning: New perspectives. London: Kogan Page, pp.32-48.

Sautter, P. (2007). Designing discussion activities to achieve desired learning outcomes: Choices using mode of delivery and structure. Journal of Marketing Education, 29, pp.122-31. http://dx.doi.org/10.1177/0273475307302014

Tsai, C.-C. (2004). Conceptions of learning science among high school students in Taiwan: A phenomenographic Aanalysis. International Journal of Science Education, 26, pp.1733-1750. http://dx.doi.org/10.1080/0950069042000230776

Virtanen, V., \& Lindblom-Ylänne, S. (2010). University students' and teachers' conceptions of teaching and learning in the biosciences. Instructional Science, 38, pp.355-70. http://dx.doi.org/10.1007/s11251-008-9088-z

Young, M. R., Klemz, B. R., \& Murphy, J. W. (2003). Enhancing learning outcomes: The effects of instructional technology, learning styles, instructional methods, and student behavior. Journal of Marketing Education, 25, pp.130-42. http://dx.doi.org/10.1177/0273475303254004

Zeegers, P. (2001). Approaches to learning in science: A longitudinal study. British Journal of Educational Psychology, 71, pp.115-32. http://dx.doi.org/10.1348/000709901158424 